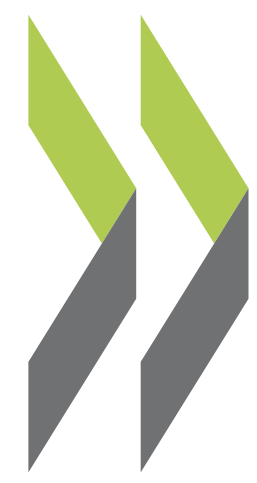

CELE Exchange, Centre for Effective Learning Environments $2010 / 13$

\title{
Can the Physical Environment Have an Impact on the Learning Environment?
}

\section{Peter C. Lippman}

https://dx.doi.org/10.1787/5km4g21wpwr1-en 


\section{Can the physical environment have an impact on the learning environment?}

By Peter C. Lippman, JCJ Architecture, New York

This paper argues in favour of challenging "best practice" generally accepted by the architectural profession by embracing a responsive design approach for creating learning environments. This approach should focus on the role of the social environment and how the physical environment may be structured to support learning.

\section{INTRODUCTION}

A responsive design approach would help designers create more innovative and sustainable learning environments. Such an approach accepts that the environment shapes the learner, and that learners influence their environment. A reasonable criticism of so-called innovative learning environments is that they are neither original nor new, and generally sustainable learning environments focus on "green building" technologies and ignore other aspects of sustainability such as social development.

A responsive design approach would embrace the educational ideology, practice theory, which describes the interaction between learner and environment, and link this to the concept of responsive commissioning, a research approach that explores the nature of the interaction between the social and physical aspects of the learning environment. The designer can then create an environment that is more responsive to the needs of 21 st century education.

\section{PRACTICE THEORY: INTERACTION BETWEEN LEARNER AND LEARNING ENVIRONMENT}

Researchers and designers of learning environments often debate whether the learner should adapt to the learning environment or whether the learning environment should adapt to them. Arguably this is the wrong question. A better question is: how does the environment shape the learner and, in turn, how does the learner influence the learning environment? In other words: what is the transactional relationship of the learning environment? This involves understanding the motivations of the learner with respect to the time and place in which s/he acquires knowledge (Lave and Wenger, 1991). The learning environment in this context is composed of the learner, other students and teachers and the physical environment.

Twenty-first century learning environments are envisioned as places where the learner is engaged in self-directed and co-operative learning activities, and the physical environment is planned so that it can be routinely re-organised to mediate learning (Partnership for 21 st Century Skills, 2002). Therefore, 20th century constructivist concepts which view the learner as active and the learning environment as 
passive should be replaced with a new perspective. Practice theory recognises that the learner and the learning environment are active (Dent-Read and Zukow-Goldring, 1997). In the constructivist setting, students learn from their own discoveries, whereas with practice theory learners are transformed and shaped by their transactions alongside others and their physical settings.

\section{INTEGRATING TECHNOLOGY FULLY INTO THE LEARNING ENVIRONMENT}

In terms of innovation, the 21st century learning ideals are not so different from Reggio Emilia and Montessori pedagogies. Both aspired to engage learners in activities with a variety of tools. Furthermore, these alterative programmes are places where faculty and students are motivated to extend their development beyond their current level of knowledge. On the whole, the goals foster critical thinking, social skills (through co-operative activities) and self-directed work. Whereas Reggio Emilia viewed the physical environment as the "third teacher" who guides learning, Montessori recognised that it must be prepared with tools to promote learning opportunities. Similarly, 21st century learning environments are using today's tools (i.e. information technologies) which are believed to guide the learner and lead development (Vygotsky, 1978).

Montessori developed teaching tools that encouraged learners to explore their environments through selfdirected and co-operative learning activities. At the time, this was an innovative and modern approach. Since the early 1900s, technology, beginning with film, then radio, television and video were brought into the learning environment (Oliver, 2004); currently, the computer, tablets and SMART boards have been introduced into instructional settings. However, none of these past or current technologies are being fully integrated into educational programmes, as was anticipated (Weiss, 2007).

One reason for this is that the design of the physical environment does not support the integration of technology (Oliver and Lippman, 2007; Weiss, 2007). How can the design professional envision a space that includes technology if the advantages and constraints of this tool have not been fully evaluated in relation to the pedagogy of the place? Otherwise put, learning environments should be programmed, planned and designed to support the intended learning activities. In addition, the spatial design of the learning environment, especially in American education, is structured around the classroom. On the whole, these spaces have not changed for decades.

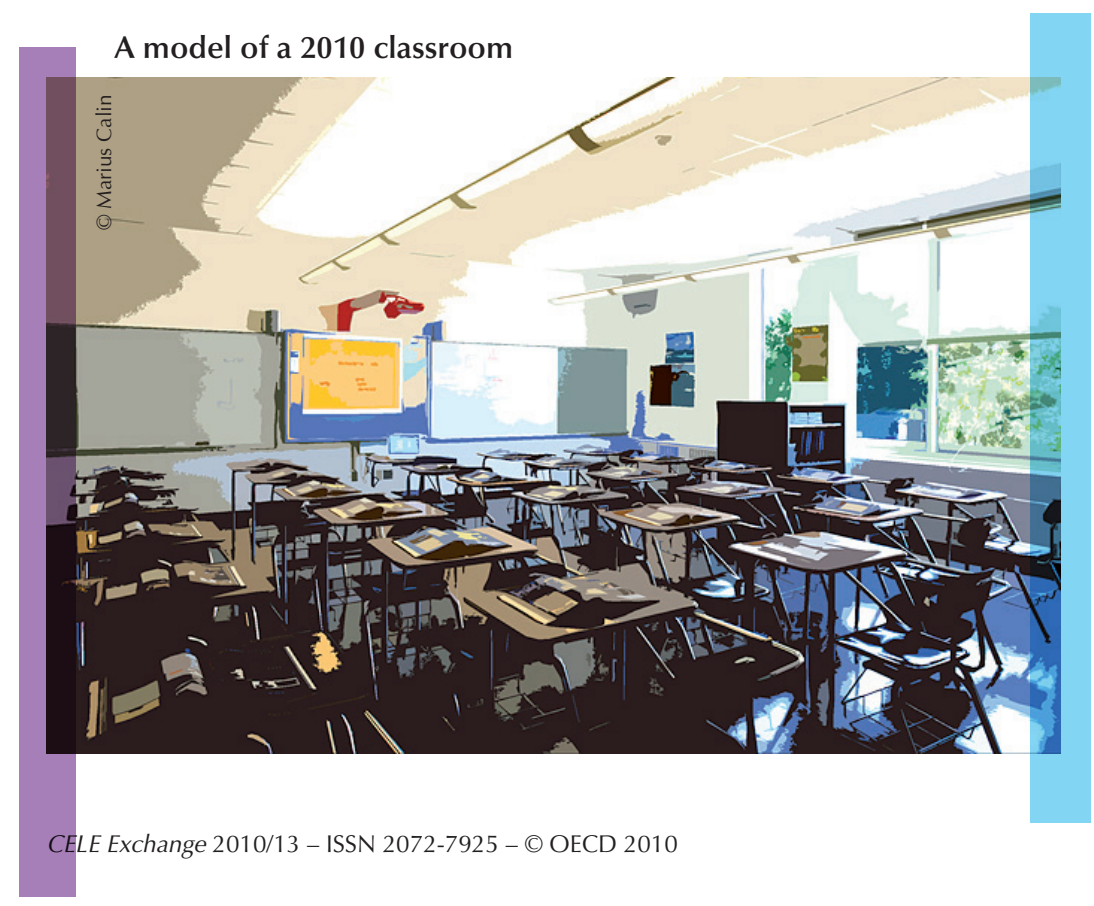

An accepted example of a 21 st century classroom reflecting how technology is programmed, planned and designed into the educational setting. Although the SMART Board has been introduced, this tool has only replaced the blackboard as the focal point of the room. In addition, this technology - along with the whiteboard - encourages only peripheral engagement, and continues to reinforce a teacher-centred learning environment. 
If technology is to be fully integrated into learning environments, the culture prevalent in institutions must change. Not only must faculty embrace it, but they must be willing to accept what it can and cannot do. The Montessori tools, for example, were planned and designed around a particular pedagogy and places were viewed as essential to learning. However, the information technologies of today have not been planned around any specific pedagogy, but rather are assumed to be integrated into any and all instructional settings (Weiss, 2007).

Collaborative classroom in the School of Engineering at the University of Melbourne

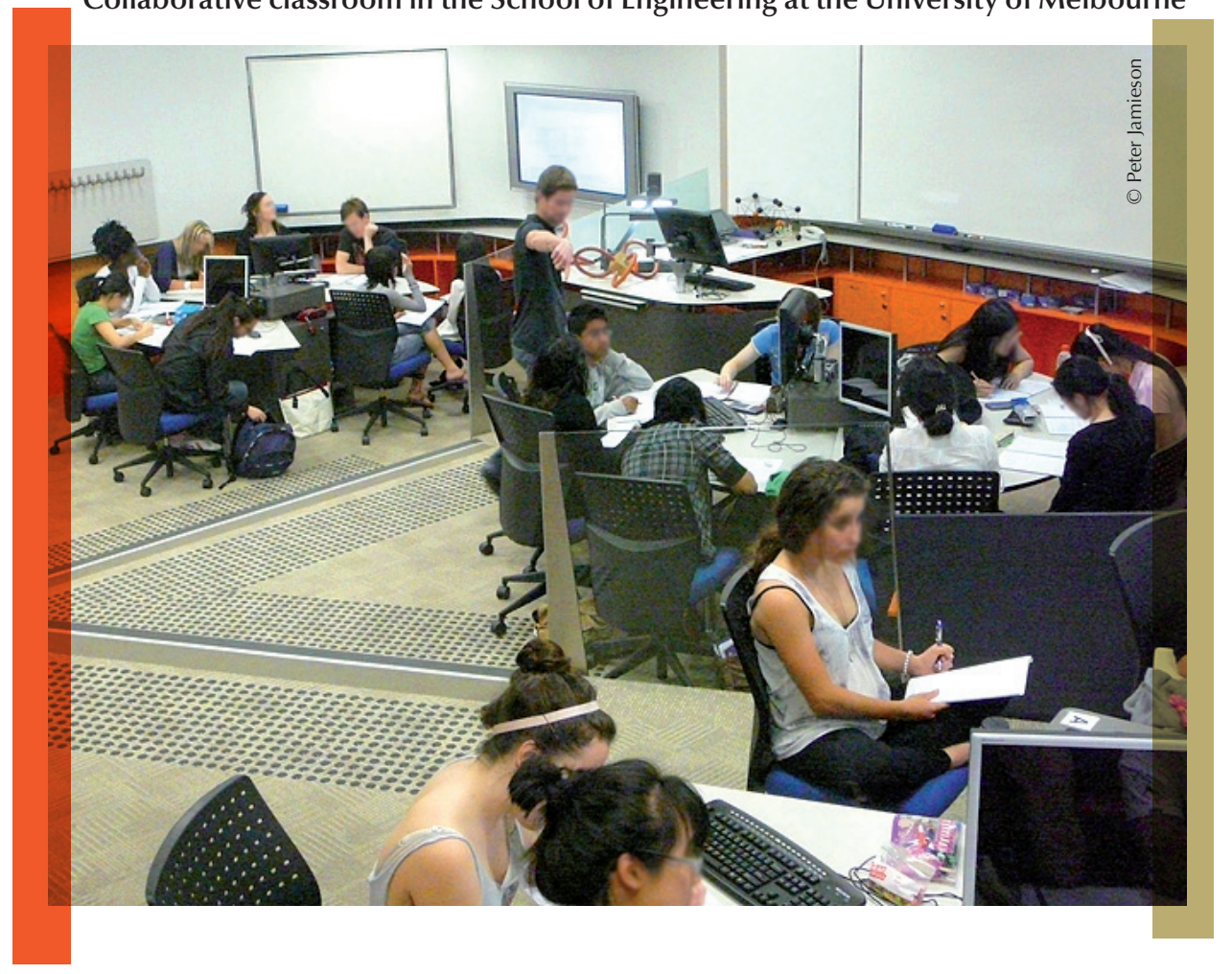

A 21 st century instructional setting that was designed to create an active learning environment to support the active learner(s). This is a renovated engineering workshop. The design reflects an integrated setting where learners are either guiding one another and/or fully engaged in acquiring knowledge for themselves, and the professor acts as a facilitator guiding the learner(s), the learning process and the subjects to be learned.

\section{SUSTAINABILITY}

As with information technologies, sustainable technologies are also understood as systems that may be incorporated into any and all buildings in similar and dissimilar contexts. Recent developments include new, alternative materials and processes for evaluating life cycle qualities, the LEED design guidelines for implementing system-specific design requirements, and production and information sources which have explored ways of promoting the trend toward reduced environmental impact. LEED is the US Green Building Council third party verification framework for implementing green building approaches. Nevertheless, this approach to sustainability rarely considers its effectiveness or its relationship with social or environmental dynamics. Additionally, interchanging the term with "green design" tends to focus attention completely on environmental impact with an underlying assumption of implicit social and economic benefits (Allacci, 2009). As a result, much of the process in evaluating sustainability does not address these seemingly secondary qualities and may promote design guidelines that are harmful to health, for example, the construction of school buildings on known toxic sites.

An exception to this trend is the concept of the triple bottom line (Elkington, 1997), which defines sustainability as balancing social, environmental and economic interests. Technological leadership in promoting the triple bottom line has been less evident. The plethora of Internet sources available for researching environmental aspects of sustainability does not extend to social and/or economic qualities. 
Instead, efforts to acquire information about social aspects of sustainability are more fragmented and typically only available from websites on social equity and justice (Allacci, 2009). Manufacturers of "green" products rarely provide information on the social impact of their activities. These can include corporate responsibility and code of conduct, social issues associated with harvesting raw material, the health implications of products, manufacturing, recycling and labour concerns.

\section{RESPONSIVE COMMISSIONING}

Responsive commissioning is an approach that considers the social environment and views the physical environment as involving the spatial design, the integration of information technologies throughout buildings and the efficiency and effectiveness of sustainable building systems. Whether responsive commissioning involves a new facility or developing an understanding about a current facility, this process begins with gathering information from key stakeholders and conducting post-occupancy evaluations of the constraints and advantages of the physical environment.

This approach may involve quantitative and/or qualitative research methods. These include researching over a number of years - graduation rates, attendance records of students and faculty, and teachers' length of service at a school. They also include more qualitative methods such as observations, interviews and/or focus groups. In addition, this approach embraces a process of participatory action research whereby the space is evaluated with stakeholders to identify dissonance between how people perceive themselves and their activities in their spaces, and how the physical environment performs. Based on this research, recommendations are made to align teaching and learning styles with how to effectively use the physical environment to engage learners. Piloting this entire process would begin with finding out what key stakeholders consider to be a great learning experience. As part of a visioning or re-visioning process, stakeholders should consider and describe how great learning experiences are occurring inside the classroom and throughout the entire school.

\section{THE RESPONSIVE DESIGN APPROACH}

The responsive design approach understands the transactional relationship between learners and their learning environment and that sustainable design does not merely signify the integration of green principles, but rather how the learning environment - social and physical - can contribute to the development of the learner. This approach does not assume that any place has been ideally designed, but it is used to reveal its advantages and constraints. This is why the designer who embraces practice theory and responsive commissioning can be said to follow a responsive design approach. Furthermore, this approach challenges current practice of architecture. Rather than dealing merely with aesthetics, the design must begin with an understanding that learning is situated in time and place (Altman, 1992). Furthermore, the design process must focus on the role of the social environment and how the physical environment may be structured to support learning and assist facilitators and learners in their work. This calls for research to examine existing settings so as to understand how they function, as well as to identify the social patterns that emerge from the activities that occur in learning environments. By conducting research, these activity patterns can be identified; they may then be used to inform the designer who then can recommend what the appropriate spatial arrangements might be.

Not only does the responsive approach value research on how the learning environment functions, but it also embraces a process which promotes a "culture of inquisitiveness" which requires rigorous analysis, animated dialogue between all participants and a working knowledge of the information 
available. It recognises that no one person possesses all of this knowledge, and as a result the role of the team takes on greater importance. Accordingly, each team member must become engaged in more issues than their usual scope of understanding. This change will only occur when designers understand the value of creating places that are not only aesthetically pleasing, but are also grounded in research. It is under these conditions that the design of the physical environment can support the transactions that take place routinely in them so that people may develop.

For more information, contact:

Peter C. Lippman

JC) Architecture

Empire State Building

350 Fifth Avenue, Suite 1029

10118 New York NY

United States

Tel.: 1 646-597-5405

E-mail: plippman@jcj.com

\section{References}

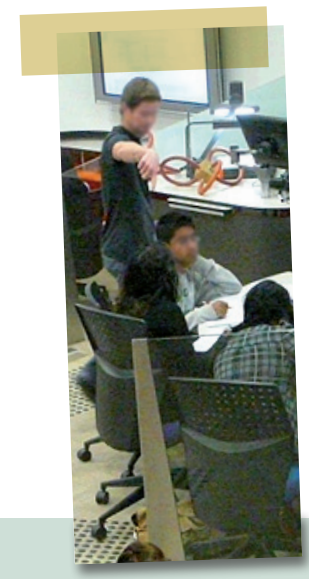

Allacci, M.S. (2009), "Revisiting Cyberspace \& Digital Technologies: A Look at Responsive and Ethical Design", paper presented at the Environmental Design Research Association (EDRA 40) conference, Kansas City, Kansas, 31 May.

Altman, I. (1992), "A Transactional Perspective on Transitions to New Environments", in Environment and Behavior, Vol. 24, Issue 2, pp. 268-280.

Dent-Read, C. and P. Zukow-Goldring (1997), "Introduction: Ecological Realism, Dynamic Systems, and Epigenetic Systems Approaches to Development", in C. Dent-Read and P. Zukow-Goldring (eds.), Evolving Explanations of Development: Ecological Approaches to Organism-Environment Systems, American Psychological Association, Washington, DC, pp. 1-22.

Elkington, J. (1997), Cannibals with Forks: The Triple Bottom Line of 21st Century Business, Capstone Publishing, Oxford.

Lave, J. and E. Wenger (1991), Situated Learning, Cambridge University Press, New York.

Oliver, C. (2004), "Teaching at a Distance: The Online Faculty Work Environment", unpublished dissertation, The City University of New York, New York.

Oliver, C. and P.C. Lippman (2007), "Examining space and place in learning environments", paper presented at the CONNECTED International Conference on Design Education, 9-12 July, University of New South Wales, Sydney, Australia.

Partnership for 21 st Century Skills (2002), "Learning for the 21st century: A report and mile guide for 21st century skills", www.21stcenturyskills.org/images/stories/otherdocs/p21up_Report.pdf.

Weiss, A. (2007), "Creating the Ubiquitous Classroom: Integrating Physical and Virtual Learning Spaces, in The International Journal of Learning, Vol. 14, No. 3, www.Learning-Journal.com.

Vygotsky, L.S. (1978), Thought and Language, MIT Press, Cambridge, MA. 


\section{ORGANISATION FOR ECONOMIC CO-OPERATION AND DEVELOPMENT}

The OECD is a unique forum where the governments of 33 democracies work together to address the economic, social and environmental challenges of globalisation. The OECD is also at the forefront of efforts to understand and to help governments respond to new developments and concerns, such as corporate governance, the information economy and the challenges of an ageing population. The Organisation provides a setting where governments can compare policy experiences, seek answers to common problems, identify good practice and work to co-ordinate domestic and international policies.

The OECD member countries are: Australia, Austria, Belgium, Canada, Chile, the Czech Republic, Denmark, Finland, France, Germany, Greece, Hungary, Iceland, Ireland, Israel, Italy, Japan, Korea, Luxembourg, Mexico, the Netherlands, New Zealand, Norway, Poland, Portugal, the Slovak Republic, Slovenia, Spain, Sweden, Switzerland, Turkey, the United Kingdom and the United States. The Commission of the European Communities takes part in the work of the OECD.

OECD Publishing disseminates widely the results of the Organisation's statistics gathering and research on economic, social and environmental issues, as well as the conventions, guidelines and standards agreed by its members.

This work is published under the responsibility of the Secretary General of the OECD. The opinions expressed and arguments employed herein do not necessarily reflect the official views of the Organisation or of the governments of its member countries.

You can copy, download or print OECD content for your own use, and you can include excerpts from OECD publications, databases and multimedia products in your own documents, presentations, blogs, websites and teaching materials, provided that suitable acknowledgment of OECD as source and copyright owner is given. All requests for public or commercial use and translation rights should be submitted to rights@oecd.org. Requests for permission to photocopy portions of this material for public or commercial use shall be addressed directly to the Copyright Clearance Center (CCC) at info@copyright.com or the Centre français d'exploitation du droit de copie (CFC) contact@cfcopies.com 